\title{
A functional pulmonary valve after tetralogy of Fallot repair: A fool's errand?
}

\author{
Emile Bacha, MD
}

\footnotetext{
From the Section of Pediatric and Congenital Cardiac Surgery, Division of Cardiac, Thoracic and Vascular Surgery, Columbia University Medical Center-New York-Presbyterian, New York, NY.

Disclosures: Author has nothing to disclose with regard to commercial support.

Received for publication Sept 25, 2017; accepted for publication Sept 27, 2017; available ahead of print Oct 27, 2017.

Address for reprints: Emile Bacha, MD, Section of Pediatric and Congenital Cardiac Surgery, Columbia University Medical Center-New York-Presbyterian, 630 W 168th St, New York, NY 10032 (E-mail: eb2709@cumc. columbia.edu).

J Thorac Cardiovasc Surg 2018;155:1161-2

$0022-5223 / \$ 36.00$

Copyright (c) 2017 by The American Association for Thoracic Surgery

https://doi.org/10.1016/j.jtcvs.2017.09.123
}

Preservation of a functional pulmonary valve (PV) by means of plasty or dilation has been the holy grail of tetralogy of Fallot (ToF) repair ever since the importance of a functional (competent but nonstenotic) PV was recognized. For most surgeons, this paradigm change occurred around the end of the last century and the beginning of this century. ${ }^{1-4}$ Prior that, the goal was to create an unobstructed right ventricular outflow tract only. The study in this issue of the Journal by the Boston group of Hofferberth and colleagues $^{5}$ on results after the use of intraoperative PV balloon dilation (IBD) presents two interesting areas of discussion, one about congenital heart surgery studies in general and one about ToF repair in particular.

Studying new procedures in pediatric cardiac surgery is inherently problematic, because prospective, randomized studies, the criterion standard, are very difficult if not impossible to accomplish because of the low number of procedures performed, the heterogeneity of both lesions and repair methods, and the ever evolving surgical techniques. Far more frequently, pediatric cardiac surgeons publish new techniques with favorable results with a short to (at best) medium follow-up. I have definitely been guilty of this myself. Updated reports on midterm to long-term outcomes of new techniques, especially when the results are unfavorable, are much rarer. Typically, the new technique dies a quiet death and is forgotten with time. I therefore congratulate Hofferberth and colleagues ${ }^{5}$ for producing a study of the highest statistical caliber with a matched cohort of patients (the next best thing to randomization) and publishing their results with a rather "negative" message. Their article is a model of how new procedures should be evaluated.

The second interesting area of discussion is whether IBD should be abandoned for ToF repairs. Indeed, it is not a technique that has been widely adopted. ${ }^{6,7}$ The study of Hofferberth and colleagues ${ }^{5}$ shows that in a substantial number of patients, IBD does not protect either from the

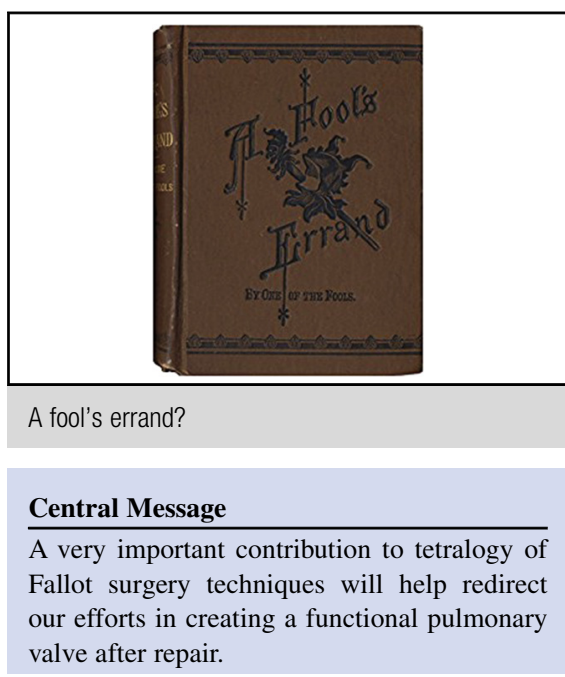

See Article page 1163 .

development of pulmonary regurgitation (PR) or from the need for subsequent PV reinterventions. Despite a shorter follow-up time, the IBD group had a higher incidence of PV reinterventions compared to the matched cohort of patients who underwent transannular patch (TAP) placement. In addition, as expected, younger age and smaller PV annulus were risk factors for PV reintervention. I am personally not entirely surprised by these findings. It has long been my clinical impression that patients who underwent IBD returned more often for a PV reintervention than did those receiving a TAP. That observation is in part why I have tried other methods to preserve PV functionality, ${ }^{8}$ especially in younger patients or patients with smaller annuli. Does that mean that the conclusion of Hofferberth and colleagues, ${ }^{5}$ namely, "The results of this study suggest that valve-sparing repair with IBD is not a suitable long-term solution to preserve $\mathrm{PV}$ function in patients with ToF," is universally true? I do not believe so. A frequent misconception is that IBD replaces the extensive commissurotomy that can and should be performed. In fact, the procedures are complementary, and IBD should never be performed without an extensive commissurotomy, leaflet thinning, and mobilization. A few other technical issues may also be important here. Although I also use antegrade balloon deployment and hand dilation under direct vision of the leaflets and the annulus, I do not use the original $120 \%$ to $140 \%$ of the preoperatively measured annulus diameter as a rule. ${ }^{9}$ Rather, I use a normalized (by body 
surface area) size of the pulmonary annulus as a guide, and I aim to reach that size within $1 \mathrm{~mm}$ with the balloon. So, if the normal PV size for the patient is $8 \mathrm{~mm}$, I will aggressively open up everything above and below the valve, open commissures into the media, thin and débride the leaflets, and then balloon to 7,8 , or $9 \mathrm{~mm}$, stopping when a leaflet tear seems imminent. I also do not use the T-shaped subannular incision as Hofferberth and colleagues ${ }^{5}$ suggest, because it could undermine and destabilize the annulus. The infundibular incision does reach as close to the annulus as possible, and I débride muscle in the immediate subvalvular area very thoroughly. Like Hofferberth and colleagues, ${ }^{5}$ at my institution we have recognized that the immediate subannular area is a frequent source of recurrent pulmonary stenosis after IBD. I then use interrupted simple sutures to secure the rounded (not pointy) patch to the subvalvular area. Of course, as I write this, I do not have objective data to show that my technique has better long-term results than those of Hofferberth and colleagues.

A tantalizing finding is that PV morphology was related to poor long-term leaflet durability and the development of PR, which I believe is the first time that this has been described. Statistics that are based on PV $z$ scores are inherently flawed, because the annulus alone does not always correlate with the effective orifice of the valve, or with the valve leaflet pathology. In other words, large PV annuli can occur in conjunction with very stenotic valves as a result of thickened and dysplastic leaflets. In my experience, the ideal patient for IBD is a patient with moderate hypoplasia of the PV annulus ( $z$ score of -2 to -3 ) and thin, nondysplastic leaflets. I realize that this represents a minority of patients with ToF.

Although it is indisputable that patients who undergo IBD face an inexorable slide towards progressive PR and RV dilation, in a more optimistic (and admittedly maybe less rigorously scientific) view, one could argue that the Kaplan-Meyer curve at 5 years shows that about $45 \%$ of patients are free of moderate PR. If your own child is one of the lucky ones who belongs in this group, IBD is a real godsend for you personally. The other option, a TAP, would have resulted in obligatory PR and an obligatory operation for PV implantation down the line. Furthermore, even though the IBD group showed a statistically higher rate of catheter-based reinterventions than did the matched TAP group, the difference in freedom from surgical reintervention was much less pronounced. Thus, were not at least some of the patients with TOF helped? Should not the argument favor, rather than a wholesale repudiation of IBD, determination as to which patients can be truly helped with this technique? Medical progress is more often about tiny steps forward than about giant leaps. It seems to me that Hofferberth and colleagues ${ }^{5}$ have helped us redirect our focus on the patients who will truly benefit from IBD, and renew our efforts towards the development of other new methods and techniques.

\section{References}

1. Murphy JG, Gersh BJ, Mair DD, Fuster V, McGoon MD, Ilstrup DM, et al. Longterm outcome in patients undergoing surgical repair of tetralogy of Fallot. N Engl J Med. 1993;329:593-9.

2. Geva T, Sandweiss BM, Gauvreau K, Lock JE, Powell AJ. Factors associated with impaired clinical status in long-term survivors of tetralogy of Fallot repair evaluated by magnetic resonance imaging. J Am Coll Cardiol. 2004;43:1068-74.

3. Al Habib HF, Jacobs JP, Mavroudis C, Tchervenkov CI, O'Brien SM, Mohammadi S, et al. Contemporary patterns of management of tetralogy of Fallot: data from the Society of Thoracic Surgeons Database. Ann Thorac Surg. 2010;90: 813-9; discussion 819-0.

4. Bacha EA, Scheule AM, Zurakowski D, Erickson LC, Hung J, Lang P, et al. Longterm results after early primary repair of tetralogy of Fallot. J Thorac Cardiovasc Surg. 2001;122:154-61.

5. Hofferberth SC, Nathan M, Marx GR, Lu M, Sleeper L, Marshall AC, et al. Valvesparing repair with intraoperative balloon dilation in tetralogy of Fallot: midterm results and therapeutic implications. J Thorac Cardiovasc Surg. 2018;155: 1163-73.

6. Vida VL, Angelini A, Guariento A, Frescura C, Fedrigo M, Padalino M, et al. Preserving the pulmonary valve during early repair of tetralogy of Fallot: anatomic substrates and surgical strategies. J Thorac Cardiovasc Surg. 2015;149: 1358-63.e1.

7. Bautista-Hernandez V, Cardenas I, Martinez-Bendayan I, Loyola H, Rueda F, Portela F. Valve-sparing tetralogy of Fallot repair with intraoperative dilation of the pulmonary valve. Pediatr Cardiol. 2013;34:918-23.

8. Sen DG, Najjar M, Yimaz B, Levasseur SM, Kalessan B, Quaegebeur JM, et al aiming to preserve pulmonary valve function in tetralogy of Fallot repair: comparing a new approach to traditional management. Pediatr Cardiol. 2016; 37:818-25. Erratum in: Pediatr Cardiol. 2016;37:990.

9. Robinson JD, Rathod RH, Brown DW, Del Nido PJ, Lock JE, McElhinney DB, et al. The evolving role of intraoperative balloon pulmonary valvuloplasty in valve-sparing repair of tetralogy of Fallot. J Thorac Cardiovasc Surg. 2011;142: 1367-73. 